\title{
Bronze Alloying Practice in Ancient China - Evidence from Pre-Qin Coin Analyses
}

\author{
A.M. Pollard and Ruiliang Liu \\ Research Laboratory for Archaeology and the History of Art, \\ School of Archaeology, University of Oxford
}

\begin{abstract}
We have reviewed the published chemical analyses of the bronze coinage produced in pre-

Qin China (before $221 \mathrm{BCE}$ ), with the aim of understanding the alloying practices which took place before these coins were cast. Conventionally it has been assumed that they were made to a 'target composition', by separately adding lead and tin to copper. However, by characterizing the composition of the different coin classes by trend lines rather than by calculating the average composition, we show that the majority of coins approximately fit a mixing line between two starting components - one containing copper, lead and tin (similar to the composition of bronze used to cast contemporary ritual vessels), and one containing only copper and lead. There is some archaeological evidence to support the existence of the latter as a raw material, in the form of fragments of $\mathrm{Cu} / \mathrm{Pb}$ alloy broken from larger cakes, previously interpreted as primitive coinage. This proposal might have implications for how we consider the perceptions and practice of alloying processes for bronze objects in pre-Qin China.
\end{abstract}

Key words: Chinese coins, chemical analysis, mixing and recycling, alloying practice

\section{Introduction to Chinese coinage}

China has some of the earliest known metal coinage. It appears that cowrie shells were used in the Shang dynasty (c. 1600 - 1045 BCE) as some form of currency (Bin 2011), and by the Western Zhou (c. 1045 - 771 BCE) these had been supplemented by imitations made from bone, jade, and, in the Eastern Zhou (c. 771 - 221 BCE), bronze. In the Chu (楚) state, south of the Yellow River, one example of such coinage known as Ant Nose Money (蚁鼻钱) was in circulation during the Warring States period (c. 475-221 BCE). Interestingly, and almost uniquely in pre-Qin China, the Chu state also used gold coinage. 
The later pre-Imperial period of China had several forms of coinage, in addition to the familiar circular coins. The earliest appears to be the Hollow handled spade (布币), which has the form of an agricultural implement (including the hollow socket to which a handle could in principle be attached), but is too insubstantial to have been functional. This link with agricultural tools is, however, significant. Writing in the late second or early first century BCE, Sima Qian (司马迁; c. 145 - 86 BCE), the Grand Historian of the Western Han (Watson 1961: vol. 2, p. 83), said:

"When the farmers, the artisans and the merchants first began to exchange articles among themselves, that was when currency came into being - tortoise shells and sea shells, gold and copper coins, knife-shaped money and spade-shaped money. Thus its origin is very old."

Prototype Hollow-handled spade money was originally the same size and shape as the original tools, and has been reported from Shang and Western Zhou tombs (Harthill 2005). The first inscriptions on the blade of the spade can be dated to around $700 \mathrm{BCE}$. The form subsequently evolved and the size was reduced. Recognized types include square shoulder spades, sloping shoulder spades and pointed shoulder spades. The hollow handle form was subsequently replaced by a completely flat form, which also showed a variety of shapes, including arched foot, pointed foot and square foot spades. Several of these shapes are associated with different states during the Warring States period, such as the pointed foot with the Zhou state, covering modern Shanxi and Hebei provinces. From the inscriptions on the spade coins, it has proved possible to identify a number of specific 'mints', or at least the locations of the city where they were cast (Harthill 2005).

Another characteristic form of pre-Qin coinage is the knife money (刀币), which copy the form of knives known to be in use during the Zhou dynasty. Several shapes have been identified, such as Qi knives, which are related to the Qi state during the Warring States, and are found in modern Shandong province. Others include Yan (pointed tip) knives, identified with the Yan state in north-east China, Needle tip knives (with longer points than Yan) from modern Hebei province, and Ming knives, named from the inscription on the blade, rather than from the much later Ming dynasty. Moulds for Ming knives have been found in the Beijing area and Shandong province, in the Yan state area (Li 1987). The final major category of pre-Imperial coinage is the circular coin, often with a square hole in the centre, 
which is clearly the precursor of the typical cash coinage of later dynasties. These appear alongside spade and knife coinage from around 350 BCE. Figure 1 illustrates some of these coin types.

A significant characteristic of Chinese copper alloy coinage is that, unlike contemporary coinage from elsewhere in Eurasia, it was cast in a mould, with any inscriptions being created as part of the moulding process. In most other currencies, the coin was cast as a blank, and then struck in a die which imposes the design and inscription. Given the non-circular shapes of much of the pre-Imperial coinage, this difference is inevitable, but it is also consistent with the characteristics of early Chinese bronze working, which, since the Shang dynasty, was focussed exclusively on complex casting in multi-part ceramic moulds, including the casting of the elaborate decorative motifs of the Shang and Western Zhou ritual bronzes (Bagley 1987, Rawson 1990). Wang (2013) gives an overview of the European language literature on numismatics in China (including a short introduction to works in Chinese). A standard introduction to the cast copper-based coinage of China in English is the work of Harthill (2005). 


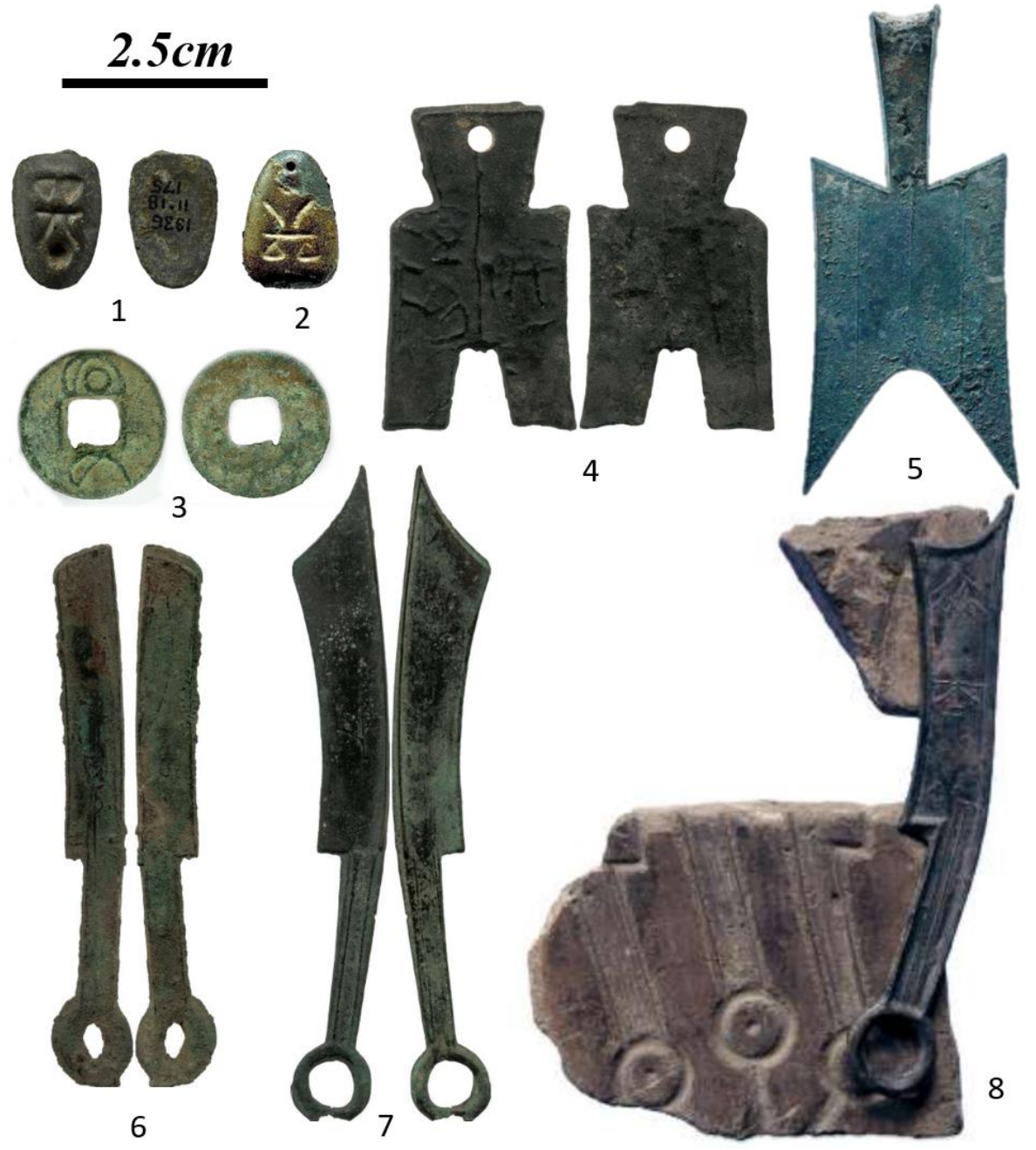

Figure 1 Different types of cons in pre-Qin China (1-2: ant-nosed money; 3: round coin; 4-5: spade money; 6-7: knife money; 8: knife money in the casting mould; courtesy of British Museum Online Gallery)

\section{Chemical Analysis of Chinese Coins}

The chemical analysis of ancient Chinese and other East Asian coinage probably started in Japan with the work of $\operatorname{Koga}(1911,1919)$. His summary of 1919 presents 113 gravimetric analyses of mostly Chinese coins, reporting (in Japanese) copper $(\mathrm{Cu})$, lead $(\mathrm{Pb})$, tin $(\mathrm{Sn})$, iron (Fe), zinc ( $\mathrm{Zn})$, arsenic (As), antimony ( $\mathrm{Sb})$, bismuth (Bi), gold (Au), silver (Ag) and nickel plus cobalt $(\mathrm{Ni}+\mathrm{Co})$. This work represents a remarkably comprehensive set of analyses, commensurate with the best analyses produced elsewhere, although it is not clear 
whether the corrosion was removed before analysis. Many subsequent analyses of Chinese coinage report a much more restrictive range of elements, sometimes only $\mathrm{Cu}, \mathrm{Pb}$ and $\mathrm{Sn}$.

Table S1 gives a list of 40 publications which contain analyses of Chinese copper-based copper coinage of all periods, many of which have been transcribed into the database (Chinese Coins) available at http://flame.arch.ox.ac.uk/public-resources/. Although the total number of analyses tabulated here is 4763 , the total number of individual coins analysed will be less than this, since there are a number of compilations which republish previous data. The most comprehensive data source for the analysis of Chinese coinage is that of Zhou (2004), which reports 1250 new analyses, plus a further c. 700 from 20 other publications. The new analyses in this paper are by X-ray fluorescence (XRF), and the data are not normalized. The average analytical total for the new XRF data is $97.4 \%$. In western scholarship, the largest contribution is that of the British Museum (Wang et al. 2005), which collects c. 700 analyses from earlier Museum publications (Bowman et al. 1989, Cowell et al. 1993, Cowell and Wang 1998) and adds more illustrations and commentary. The majority of the British Museum data are collected by XRF (divided into those in which the surface was abraded before analysis (XRFA: $\mathrm{n}=421$, average analytical total 99.8\%), and those which were unabraded (XRFU: $\mathrm{n}=85$, average analytical total 99.9\%) The remainder $(\mathrm{n}=60)$ were done by atomic absorption spectrometry (AAS), in which copper was not directly determined. Many of the publications listed in Table $\mathrm{S} 1$ have been reproduced in a summary volume (Zhou and Dai 2002), which republishes 28 papers in Chinese and 12 in English.

It is inevitable that, by using a chemical database compiled from data acquired over a period of many decades, the quality of the data will be variable. This disadvantage has to be offset against the benefit of having a much larger database, and, providing that the data are interpreted cautiously, we believe that such a database can still prove useful. This is extensively discussed in Pollard et al. (2018, chapter 3), which concludes that, by restricting the questions to those that can be addressed using suitable robust numerical approaches (i.e., those which are unlikely to be sensitive to underlying variations in data quality), such heterogeneous datasets can still be useful (see also Liu 2016 chapter 3). The most likely source of inconsistency is in the comparison of trace element data. In the work presented here, we have only used large-scale variations in the major element data (copper, tin and lead) and are therefore satisfied that the data are sufficiently robust to draw the conclusions set out below. 


\section{Alloying of Pre-Qin Coinage}

Many of the papers listed in Table S1 include discussions of the compositions of the various categories of Pre-Qin coinage, but almost all of the discussion of these coins is based on producing average compositions for each class of coin. A cursory glance shows that the three main alloying elements $(\mathrm{Cu}, \mathrm{Sn}$ and $\mathrm{Pb})$ vary widely, even within a specific type of coinage, so that a simple average does not adequately characterize the nature of the metal. For example, in Zhou's compilation of c. 500 pre-Qin coins (Zhou 2004), the copper ranges from 0.1 to $99.31 \%$, the lead from 0.19 to $95.65 \%$, and the tin from 0 to $18.8 \%$. In order to determine the alloying practices for the manufacture of these coins (by which we mean the way in which the constituent metals are mixed at the point of casting, Pollard et al. 2019), we have chosen to look at trend lines, rather than averages.

Table S1 lists the total number of analyses of pre-Qin coins in each of the published papers (c. 1200), but many are repeated in subsequent publications. For this study (apart from the earliest period) we have mostly chosen to rely on the data compiled by Zhou Weirong (2004), who lists the analyses of 520 pre-Qin coins. This is because these coins are catalogued in a systematic way (in some of the earlier publications, such coins are often too poorly described to assign them confidently to a particular type), and it also reproduces most of the useable data produced before 2004. Subsequent publications (e.g., Wang et al. 2005) add very little additional data for the pre-Qin period (in this case, only 6 coins).

Figure 2 shows a plot of $\% \mathrm{Sn}$ vs $\% \mathrm{~Pb}$ for coins dated to the Spring and Autumn period of the Eastern Zhou (c. 771 to 475 BCE), thus reflecting the earliest analysed copper coinage from China. In this case, the coin data are taken from Koga (1919; 4 coins), Chikashige (1920; 7 coins), Dai and Zhou (1992; 5 coins) and Dai and Zhou (1998; 12 coins), and the comparative data on Eastern Zhou ritual bronzes are from the Sackler Collection (So 1995). Given that the coin data were obtained over a period 80 years, there are inevitably variations in analytical methodology and quality, but the broad trends appear to be consistent. In particular, as noted above, in Koga's data it is not clear that the corrosion was removed, which is likely to result in higher levels of tin than would be present in the uncorroded metal. Nevertheless, the figure shows that the coins typically have more lead than the vessels, and 
that 15 of the coins contain significant tin (>5\%), whereas 13 have tin below $2 \%$, with many recorded as zero. The maximum level of tin in the coins reaches about $18 \%$ (but see previous comment), which is very similar to the highest tin seen in the vessels, but the lead concentration reaches c. $55 \%$ in the coins, whereas the maximum in the vessels is c. $32 \%$. The significance of the existence of coins with less than $2 \%$ tin is discussed below.

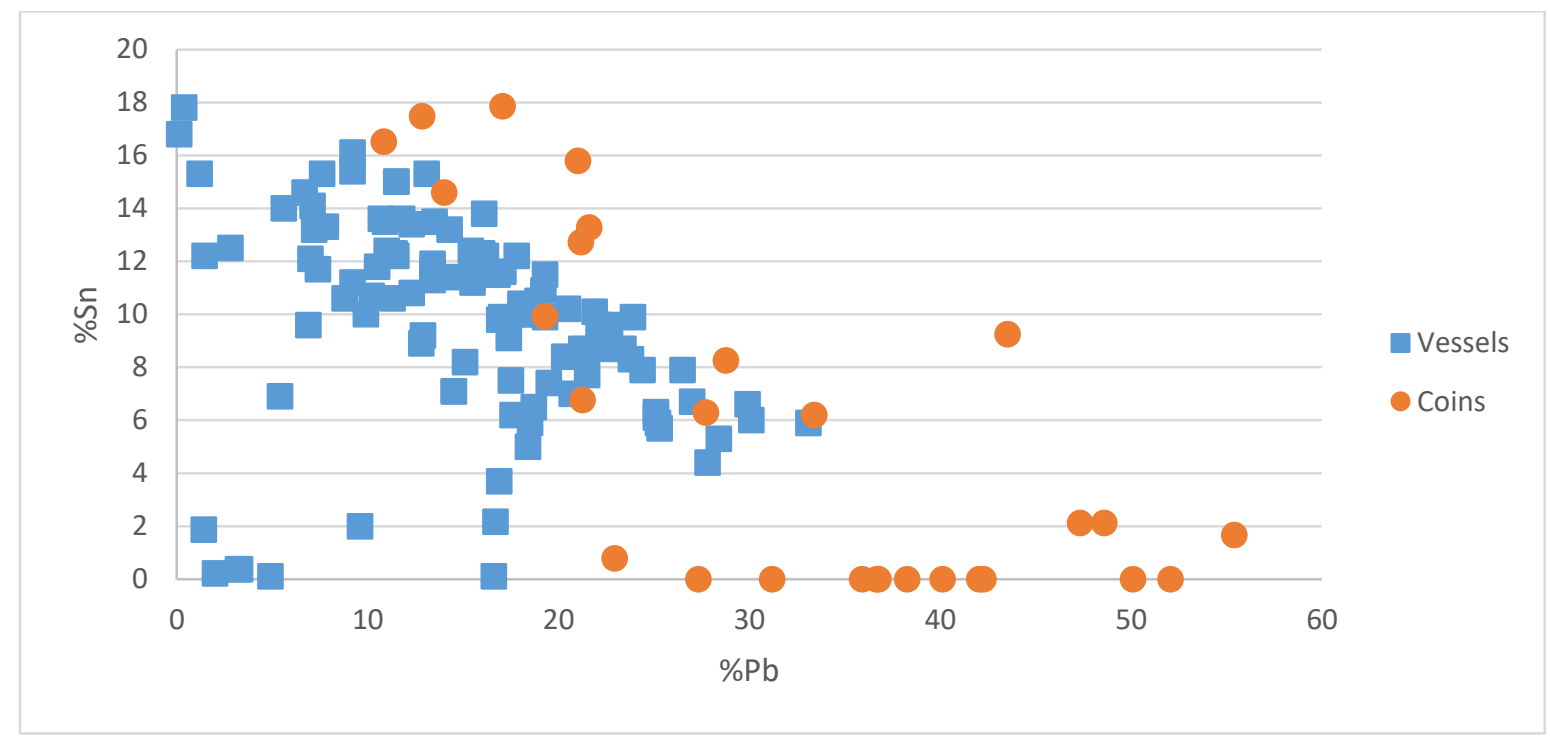

Figure 2. \%Pb vs \%Sn for Eastern Zhou vessels (c. 771-256 BCE) and Spring and Autumn period (c. 771 to 475 BCE) coins (sources as in text).

In the subsequent Warring States period (c. 475-221 BCE), Zhou (2004) presents data on four broad classes of coin:

i. Spade coins (布币), divided into Hollow handle spades (21 coins), pointed-foot and similar square foot spades (17), square foot spades (27) and arched-foot spades (55), and other spades (4).

ii. Knife coins (刀币), divided into Yan knives (178), Qi knives (35), Straight knives (16) and other knives (6);

iii. Ant nosed money (蚁鼻钱), associated with the Chu state;

iv. Round coins, divided into Yi hua (19), Banliang and Liangzao (13), Yuanzi (4), and Min yue (2). 

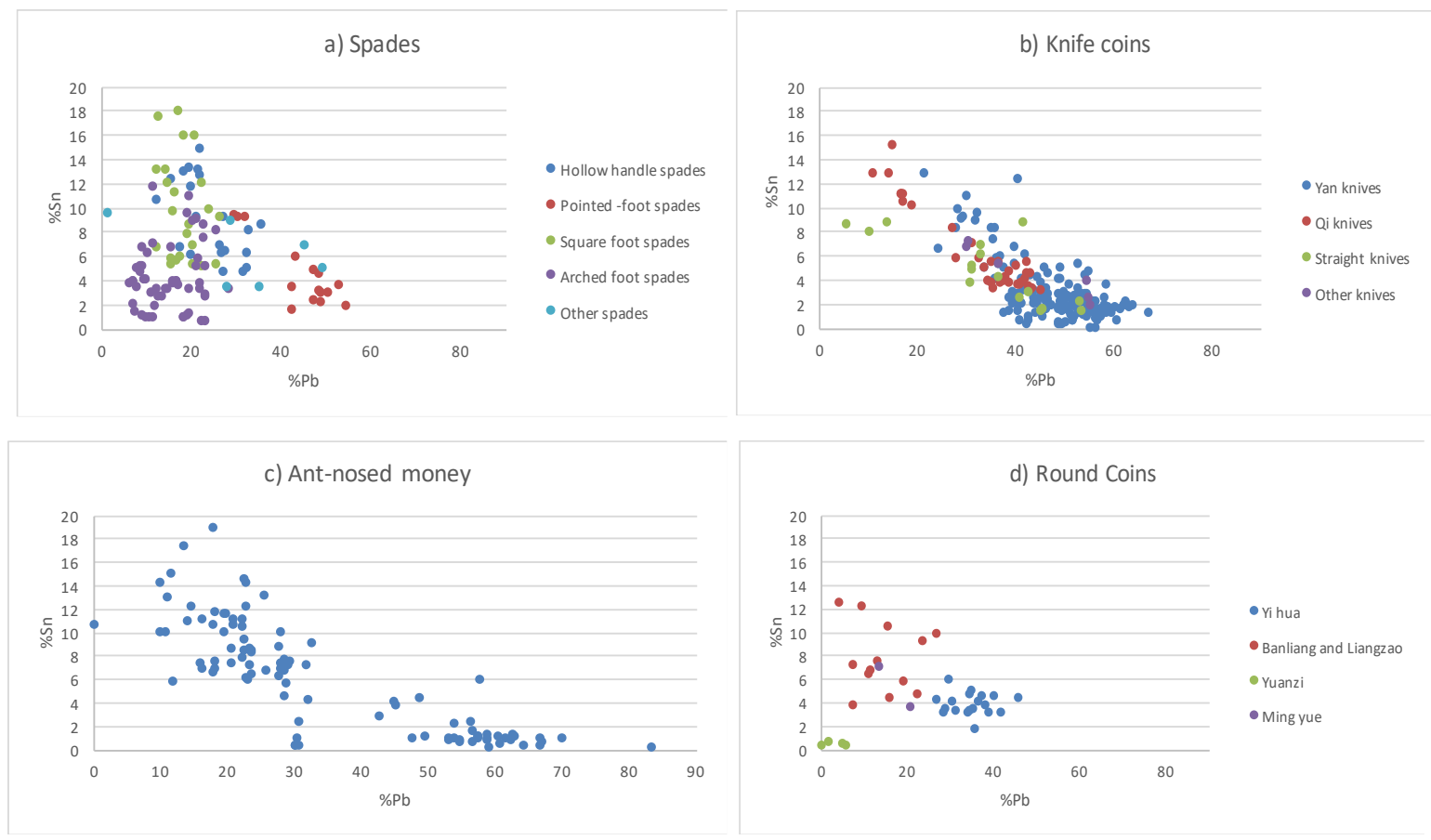

Figure 3. Plots of \%Sn vs \%Pb for a) spade coins, b) knife coins, c) ant-nosed money and d) round coins. Data re-plotted from Zhou (2004).

Figure 3 show plots of $\% \mathrm{Sn}$ vs $\% \mathrm{~Pb}$ for each of these categories, divided into the various subcategories as given by Zhou (2004). As noted above, some of these sub-categories can be explicitly associated with particular States (e.g., Qi and Yan knives), so the categorization shown in Fig 3 is also a first approximation to a regional categorization. A striking feature, seen most clearly in the knife coins, is the strong anti-correlation between tin and lead. It is clear from this figure that an average composition for, say, the Yan knives, would be an inadequate description of their composition as a group, and it is best described by a trend line, reflecting a linear relationship between lead and tin, discussed further below. At first glance, the figure for the spade coins (Fig. 3a) shows a different structure, but this resolved in Figure 4, in which the arched-foot spades are plotted separately from the others. This shows that the majority of spade coins fit the general pattern of an anti-correlation between tin and lead, with the arched-foot spades (associated with the Wei State) behaving differently. The significance of this in terms of possible alloying practice is discussed below. 


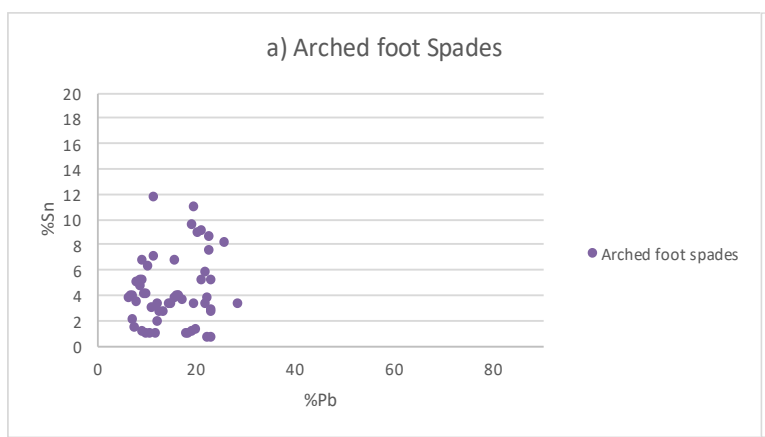

b) Other Spades

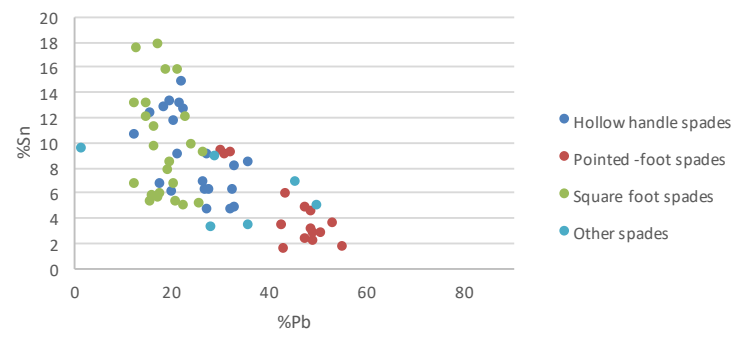

Figure 4. \%Sn vs \%Pb for a) arched-foot spades and b) other spade coins (re-plotted from Zhou (2004).

The overarching characteristic of these coins is that most of them have some content of tin $(>2 \%)$, together with a strong inverse relationship between tin and lead - as the tin decreases, the lead increases, to the point where, for some coins, the lead is above $50 \%$ and the tin is below $2 \%$. In the whole dataset of pre-Qin coins produced by Zhao (2004) (n approximately 500), the correlations are:

$$
\begin{aligned}
& \mathrm{Cu}-\mathrm{Pb}: \mathrm{r}=-0.965(\mathrm{t}=82.1) \\
& \mathrm{Cu}-\mathrm{Sn}: \mathrm{r}=0.443(\mathrm{t}=11.03) \\
& \mathrm{Sn}-\mathrm{Pb}: \mathrm{r}=-0.597(\mathrm{t}=16.61)
\end{aligned}
$$

For $n=500$, the critical value of $t$ (two tailed, 95\% confidence) is 1.96 . Thus all these correlations are significant at the $95 \%$ confidence level. The strongest relationship is a negative correlation between copper and lead, showing that as lead increases copper goes down. The much weaker relationship between copper and tin is positive, indicating that those coins with the highest copper also tend to have the highest tin. Tin and lead are also negatively correlated, showing that tin decreases as lead increases, but not as strongly as does copper.

How can we interpret these correlations? The dominant relationship is between copper and lead, which suggests that copper is replaced by lead in a dilution process - it could be the other way round (i.e., lead diluted by copper), but for simplicity we will discuss it in terms of dilution of copper, and the implications would be the same. The fact that copper is weakly positively associated with tin suggests that it might not, however, be a simple dilution of copper with lead, but is more likely to be one of bronze (copper plus tin) diluted with lead. 
The negative correlation between lead and tin rules out the possibility of the simple dilution of copper with a lead-tin alloy (in which case lead and tin would be positively correlated). We further note that if we are correct in assuming that the process is a dilution of a bronze with lead, then those coins with the highest values of tin and the lowest values of lead should approximate the composition of the the bronze component before the lead is added.

Inspection of Figs. 2, 3 and 4 suggests that the highest tin values in the pre-Qin coinage are around $18 \%$, and the corresponding lead value is around $15 \%$. This composition is close to that of the Eastern Zhou ritual vessels with the highest tin values - shown in Figure 1 to be approximately $10 \%$ lead, $18 \%$ tin and $72 \%$ copper. For the purposes of the modelling described below, we assume that this might reflect the composition of the undiluted raw 'stock bronze'. This does not necessarily imply that coins were made from 'recycled' ritual vessels (although that could be true), simply that the stock bronze alloy for coins was similar to that used for making ritual bronzes.

The majority of the coins lie on a curve which suggests that this stock metal has been diluted with lead, explaining the gradual decrease in tin and increase in lead. Figure 5 shows the effect on the tin and lead of some modelled mixing to simulate this situation. The starting point for this model is arbitrarily chosen to be an alloy of composition $80 \% \mathrm{Cu}, 15 \% \mathrm{Sn}$ and $5 \% \mathrm{~Pb}$, to which increasing proportions of a diluent are added and the compositions renormalised. The proportions of diluent are calculated step-wise from $0,+10 \%$ (by weight relative to the original mass), $+20 \%$ (relative to original mass), and so on up to $+1000 \%$, which corresponds to an addition of ten times the weight of diluent compared to the original sample. In Figure 5 a number of diluting materials have been modelled - pure $\mathrm{Pb}, 50 / 50$ $\mathrm{Pb} / \mathrm{Sn}, 90 / 10 \mathrm{~Pb} / \mathrm{Sn}$ and $50 / 50 \mathrm{Cu} / \mathrm{Pb}$. The numerical data for the models concerning pure lead and $50 / 50 \mathrm{Cu} / \mathrm{Pb}$ are given in the Appendix. 


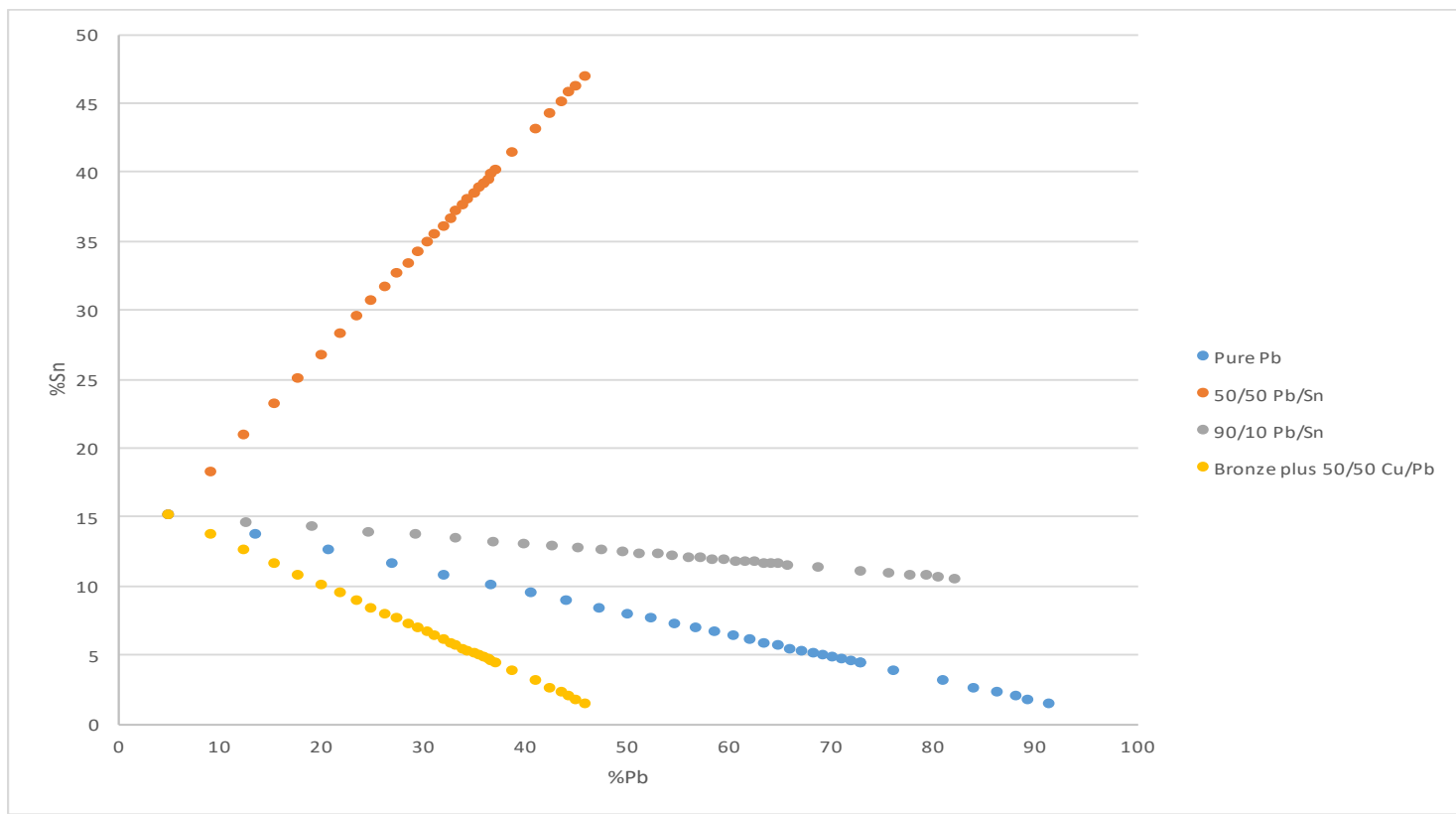

Figure 5. Modelled composition of an alloy of $80 \% \mathrm{Cu}, 15 \%$ Sn and 5\% Pb diluted with a) pure $\mathrm{Pb}, \mathrm{b}$ ) 50/50 $\mathrm{Pb} / \mathrm{Sn}, 90 / 10 \mathrm{~Pb} / \mathrm{Sn}$ and $50 / 50 \mathrm{Cu} / \mathrm{Pb}$.

As expected, dilution with $50 / 50 \mathrm{~Pb} / \mathrm{Sn}$ shows an increase in both lead and tin, and so does not correspond to any of the patterns seen in the coin data shown in Figs 2-4. Dilution with pure lead shows a gradual decrease in tin and an increase in lead. Dilution with $90 / 10 \mathrm{~Pb} / \mathrm{Sn}$ shows a more gradual decrease in tin and a slower increase in lead. The most rapid decrease in tin is caused by the addition of $50 / 50 \mathrm{Cu} / \mathrm{Pb}$. This is because, although the percentage of tin falls equally with the diluent containing only lead, the percentage of lead rises slower if the diluent is $50 / 50 \mathrm{~Pb} / \mathrm{Cu}$ than it does with $100 \% \mathrm{~Pb}$, and so the plot of $\% \mathrm{Sn}$ vs $\% \mathrm{~Pb}$ falls more rapidly.

Figure 6 shows all of the pre-Qin data with two of these trend lines superimposed (an alloy of $80 \% \mathrm{Cu}, 15 \% \mathrm{Sn}$ and $5 \% \mathrm{~Pb}$ diluted with a) pure $\mathrm{Pb}$, and b) $50 / 50 \mathrm{Cu} / \mathrm{Pb}$ ). It is immediately apparent that the dilution with pure lead does not reduce the proportion of lead in the coins as steeply as indicated by the trend line seen in the majority of the coins, whereas dilution with $50 / 50 \mathrm{Cu} / \mathrm{Pb}$ follows the composition of the majority of the coins fairly closely. In justification of this observation, it is important to remember that the majority of coins in Figure 6 fall close to the negative diagonal from approximately $15 \% \mathrm{Sn}, 0 \% \mathrm{~Pb}$ to $0 \% \mathrm{Sn}$, $60 \% \mathrm{~Pb}$, as shown in Figures 2-4. As noted above (Fig. 4a), the coins which fall below this diagonal are principally the arched-foot spades of the Wei state, for which a different manufacturing process is considered below. Before considering further the implications of 
this suggestion, it is important to ask if the observed trend lines could be an artefact of the constraint that $\% \mathrm{Cu}+\% \mathrm{~Pb}+\% \mathrm{Sn}=100$ (i.e., an artefact of the Unit Sum Problem identified by Aitchison (1986)). One obvious observation is that in a ternary $(\mathrm{Cu}-\mathrm{Pb}-\mathrm{Sn})$ system there is bound to be an inverse relationship between two pairs of variables, given that if one component goes up the other two must go down. This issue is addressed in detail in the Appendix, where it is shown that the trends discussed here are not an artefact of the Unit Sum problem.

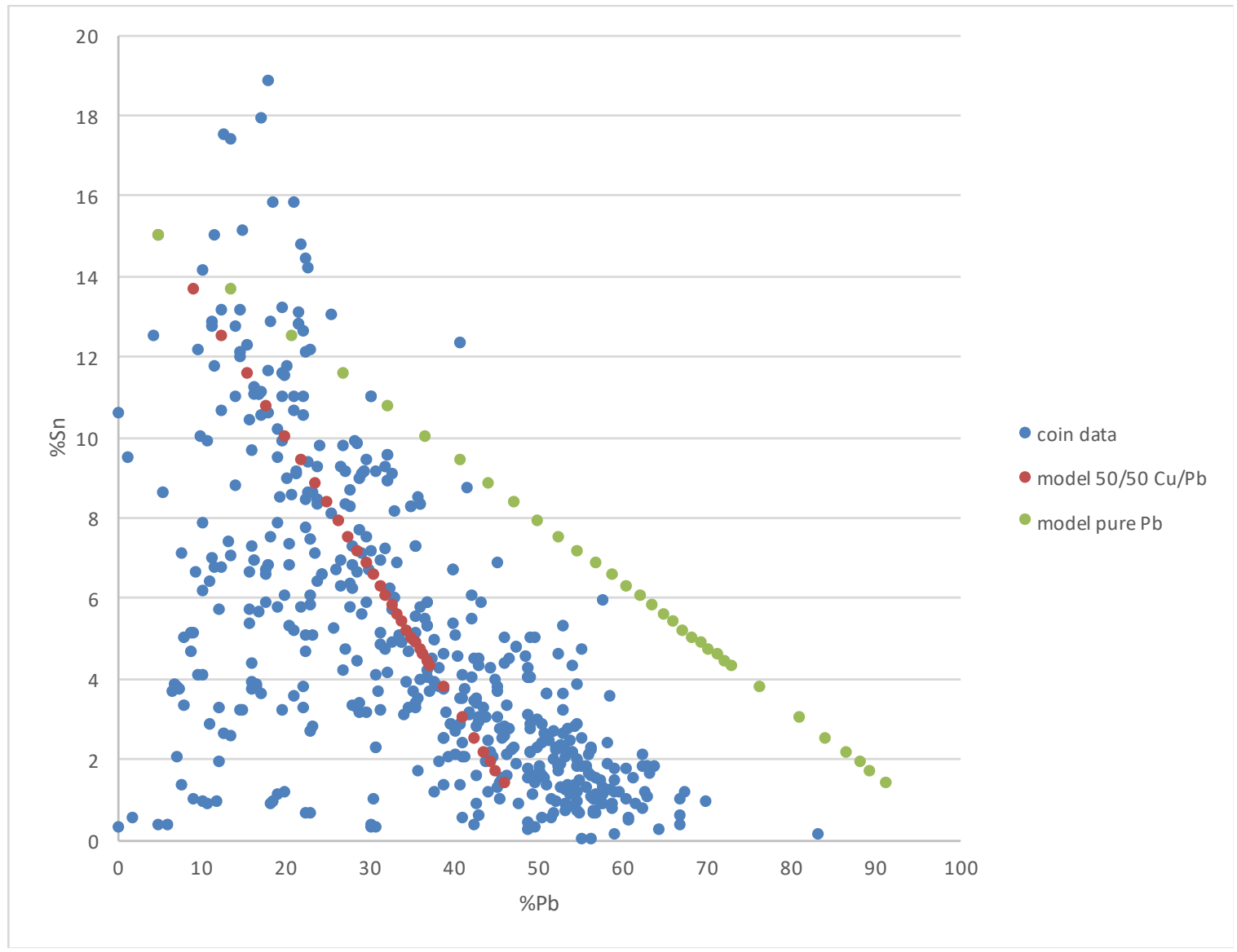

Figure 6. \% Sn vs \% Pb for all pre-Qin coinage, with superimposed trend line for an alloy of $80 \% \mathrm{Cu}, 15 \%$ Sn and $5 \% \mathrm{~Pb}$ diluted with a) pure $\mathrm{Pb}$, and b) 50/50 $\mathrm{Cu} / \mathrm{Pb}$.

\section{Discussion}

Of the limited number of models shown in Figures 5 and 6, it would appear that the 'best fit' for the composition of the majority of the pre-Qin coinage is one which starts with an alloy containing approximately $80 \%$ copper, $15 \%$ tin and 5\% lead, diluted with increasing quantities of an alloy consisting of approximately 50/50 copper and lead. Undoubtedly this 
modelling could and should be improved (by altering the starting composition and the ratio of copper to lead in the diluent for each class of coin) to give a better fit to the data, but that is not the primary purpose of this paper. The aim here is simply to show an alternative way of viewing the alloying practices which might have given rise to the data, without assuming that the aim was to conform to specific target compositions. For the majority of pre-Qin coin types, the data are consistent with a simple two component dilution model between a stock bronze $(\mathrm{Cu} / \mathrm{Pb} / \mathrm{Sn})$ and a leaded copper $(\mathrm{Cu} / \mathrm{Pb})$.

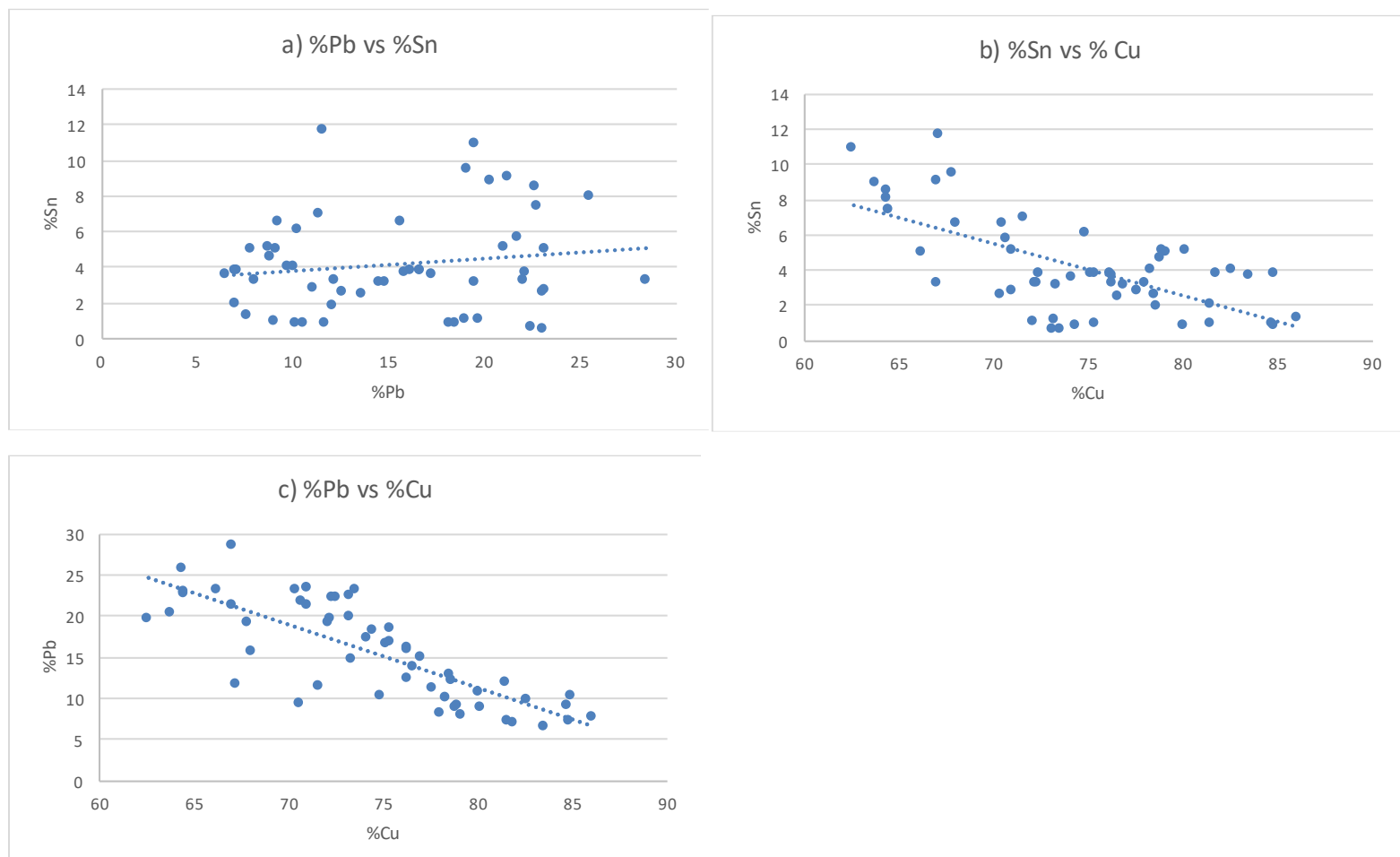

Figure 7. Correlation structure for Arched-foot spade coins a) $\% \mathrm{Sn} v \mathrm{~s} \% \mathrm{~Pb}, \mathrm{~b}) \% \mathrm{Sn} v \mathrm{~s} \% \mathrm{Cu}$, c) $\% \mathrm{~Pb} v \mathrm{~s} \% \mathrm{Cu}$

One major group of coins which does not conform to this model are, as noted above (Fig. 4a), the arched-foot spades, associated with the Wei state during the Warring States period (n approximately 50). These seem to have been made to a different 'recipe'. The correlation structure within this group of coins is quite different from that shown by the main body of data, as shown in Figure 7. Here all three correlations are shown, and tabulating the correlation data shown in these three figures gives the following:

$$
\mathrm{Cu}-\mathrm{Pb}: \mathrm{r}=-0.752(\mathrm{t}=8.07)
$$




$$
\begin{aligned}
& \mathrm{Cu}-\mathrm{Sn}: \mathrm{r}=-0.629(\mathrm{t}=5.74) \\
& \mathrm{Sn}-\mathrm{Pb}: \mathrm{r}=0.095(\mathrm{t}=0.675)
\end{aligned}
$$

For $\mathrm{n}=50$, the critical value of $\mathrm{t}(95 \%$, two tailed) is 2.009 . Thus the negative correlations between $\mathrm{Cu}-\mathrm{Pb}$ and $\mathrm{Cu}-\mathrm{Sn}$ are significant at the $95 \%$ confidence level, but that between $\mathrm{Sn}$ $-\mathrm{Pb}$ is not. These figures should be compared with those given above for all pre-Qin coinage. This lack of correlation between lead and tin in the Wei state coinage, in conjunction with significant negative correlations between copper and both tin and lead, is highly informative in this context. It implies that lead and tin are being independently added to the coinage. The simplest explanation of the alloying process used here is that this reflects independent additions of both tin and lead in variable proportions to a copper rich base. In the context of this paper, this gives us a strong indication of what an alternative (and perhaps initially more intuitive) alloying recipe involving independent addition of lead and tin to copper would look like in terms of major element correlations, and allows us to dismiss it as a possibility for the majority of pre-Qin coinage.

How realistic is a two-component-dilution model for the majority of these coins, in which one component contains copper, lead and tin, and the other contains only copper and lead? It explains the major trends in most of the data (apart from the arched-foot spades, which fortuitously, allows us to see an alternative model in the data), and also why most coins contain some tin - even when the levels of tin are unlikely to exert any influence on the physical or visual properties of the coins. Even though the tin-containing component is quite similar in composition to some of the contemporary Eastern Zhou ritual vessels, it does not necessarily imply that coins were made from melted down vessels - merely that there existed some sort of 'stock alloy' for bronze casting, which for coin-casting was most often diluted, for either economic or physical (fluidity) reasons. How do we interpret the apparently fixed ratio of copper to lead in the diluting metal - was it a pre-formed alloy of copper and lead? It is here that we return to the data shown in Figure 2, which includes 12 samples published by Dai and Zhou (1998), in which they are described as 'pieces of bronze used as primitive currency' (This paper is a translation of Dai and Zhou (1995), originally published in China Numismatics). Dai and Zhou discuss a 'large number of pieces of bronze ... unearthed in sites of Western Zhou and Spring and Autumn period (c. 1045 - 475 BCE) along the lower reaches of the Yangtze River in what was then the State of Wu'. They list finds from more than 10 sites (mostly tomb contexts), often in 'hoards' within ceramic jars, containing 
between 1 and $150 \mathrm{~kg}$ of metal. The form is described as pieces resulting from the breakage (or cutting) of 'large bronze cakes with different shape and weight'; the pieces themselves weigh between $10 \mathrm{~g}$ and $1 \mathrm{~kg}$. Crucially, they contain copper and lead, but no tin - they have a range of compositions, but the average is $60 \% \mathrm{Cu}$ and $40 \% \mathrm{~Pb}$. Dai and Zhou (1998) argue that they are deliberately made (since the lead is much higher than would be expected by accidental smelting of a copper ore containing traces of lead), but that they were not the raw materials for bronze casting (since they contain no tin). Their composition is at the extreme (high lead/low tin) end of the range of analysed pre-Qin coinage, and so they conclude that they were 'deliberately made to be used as a primitive currency.' Here we endorse this interpretation, but suggest a significant extension to this conclusion - that these 'primitive lumps' are in fact one of the two raw materials used to make coinage - the 'diluting metal' (without tin) added to a 'stock bronze' (containing tin). If this is true, it poses a number of archaeological and numismatic questions:

i) Why use two pre-prepared alloys rather than three pure metals? Potentially it simplifies the preparation of the alloy before casting, requiring only two components rather than three. It would consequently require less metallurgical skill to prepare the casting alloy, but might be more related to the control and supply of raw materials rather than any skill limitations on behalf of the coin producers.

ii) It poses significant questions about how the production of coins was organized. The apparent ubiquity of the practice (over several States and several hundred years) strongly suggests some unified practical approach to casting coins, which is unlikely to be the consequence of a large number of privately-owned mints. Equally importantly, why was the practice in the Wei state during the Warring States period different? - arched-foot spade coins appear to have been made by independent additions of lead and tin to copper.

iii) How did the metal economy work? Where were the sources of the raw materials, where were the two raw material ingots created, and how were they supplied to numerous mints? How much do the data reflect recycling of coinage, perhaps with dilution, against the use of new metal?

These questions can only be answered by further archaeological and chemical research on a wider range of coins and coin production sites in pre-Qin China. 


\section{Conclusion}

A study of the chemistry of pre-Qin coinage, focussing on correlations between elements rather than considering averages, has suggested that the composition of the majority of coin types can be explained by a model in which a 'stock bronze' (of approximate composition 70 $-80 \%$ copper, 5 - $10 \%$ lead and $15-20 \%$ tin) is diluted with an alloy containing approximately equal weights of copper and lead. Importantly, the Wei State arched-foot spades show a completely different chemical correlation structure, which probably represents the direct and independent addition of lead and tin to copper, and which allows us to eliminate this as a model for the majority of pre-Qin coins. Consideration of the 'Unit Sum' problem has shown that these trend lines are not an artefact of the compositional constraint, and a series of numerical simulations show the plausibility of a binary model. The physical evidence for a two-component model comes from the observation that there is a similarity between the composition of the most tin-rich coins and those contemporary Eastern Zhou ritual vessels with the highest tin, suggesting the existence of a 'stock bronze' containing copper, lead and tin, which is diluted to make most coins. The evidence for the binary $\mathrm{Cu} / \mathrm{Pb}$ diluent in this 'recipe' comes from a reconsideration of a small number of analyses of early 'primitive lumps' from the Wu State, which are irregular fragments of copper-lead cakes, previously interpreted as primitive coinage. Perhaps further archaeological research focussing on known sites of coin casting in other States may help to support or refute this interpretation. If this model proves to be plausible, however, it leads to further speculation about the possible 'recipes' for bronze casting more generally in pre-Qin China, given the similarity seen between coins and ritual vessels in Figure 2. Is it possible that even ritual bronzes were cast using an alloy constituted from a mixture of two basic raw materials - one containing copper plus tin and lead, and one containing only copper and lead? This question requires a re-consideration of the existing chemical data on pre-Qin Chinese bronzes.

\section{Acknowledgement}

This work is funded by European Research Council Horizon 2020 (ERC advanced project FLAME, Flow of Ancient Metal Across Eurasia, 670010). 


\section{References}

AITCHISON, J., The Statistical Analysis of Compositional Data. Blackburn Press, Caldwell, NJ (1986). (reprinted 2003).

BAGLEY, R.W., Shang Ritual Bronzes in the Arthur M. Sackler Collections. Arthur M. Sackler Foundation, Washington, D.C. (1987).

BIN YANG, The rise and fall of cowrie shells: The Asian story. Journal of World History 22, $1-25(2011)$.

BOWMAN, S.E., COWELL, M.R. and CRIBB, J., Two thousand years of coinage in China: an analytical survey. Journal of the Historical Metallurgy Society 23(1), 25-30 (1989).

CHIKASHIGE, M., The composition of ancient eastern bronzes. Journal of the Chemical Society 117, 917-922 (1920).

COWELL, M. and WANG, H., Metal supply for the metropolitan coinage of the Kangxi period (1662-1721). Numismatic Chronicle 158, 185-196 (1998).

COWELL, M.R., CRIBB, J., BOWMAN, S.G.E and SHASHOUA, Y., The Chinese cash: composition and production. In Archibald, M.M. and Cowell, M.R. (eds.), Metallurgy and Numismatics 3, pp.185-198, Royal Numismatic Society Special Publication 24, London (1993).

DAI ZHIQIANG and ZHOU WEIRONG, 中国早期的称量货币：青铜一长江下游地区出 土青铜块的科学验证 (The weighting currency of China in the early time: bronze - a scientific test to the bronze lumps excavated from lower reaches of Yangtze River). Zhongguo qianbi (China Numismatics) 1995(2), 3-7 (1995). 
DAI ZHIQIANG and ZHOU WEIRONG, A study of the pieces of bronze used as primitive currency in Ancient China. In Oddy, A. and Cowell, M. (eds.), Metallurgy in Numismatics 4, pp. xx-yy, RNS Special Publication 30, London (1998).

DAI ZHIQIANG and ZHOU WEIRONG, Studies of the alloy composition of more than two thousand years of Chinese coins (5th century BC-20th century AD). Journal of the Historical Metallurgy Society 26(2), 45-55 (1992).

HARTILL, D., Cast Chinese Coins. A Historical Catalogue (Victoria BC: Trafford Publishing, 2005).

KOGA, N., A table of the Chemical analysis of old Japanese and Chinese copper coins assayed by Mr. Koga. Kokogaku Zasshi (Journal of the Archaeological Society of Nippon) 9(7), 35-52 (1919).

KOGA, N., Chemical composition of ancient coins. Suiyōkai shi (Journal of mining and metallurgy, Kyoto) 1, 517 (1911).

LI, L., The discovery for the Yan knife moulds at Chengde, Hebei. Kaogu 1987(6): 196.

LIU, R., Capturing changes: applying the Oxford system to further understand the movement of metal in Shang China, DPhil Thesis, University of Oxford (2016).

POLLARD, A.M., BRAY, P., CUÉNOD, A., HOMMEL, P., HSU, Y.-K., PERUCCHETTI, L., POUNCETT, J. and LIU, R., Beyond Provenance: New Approaches to Interpreting the Chemistry of Archaeological Copper Alloys. Leiden University Press, Leiden (2018).

POLLARD, A. M., LIU, R., RAWSON, J., and Tang, X. From alloy composition to alloying practice: Chinese bronzes. Archaeometry, 61(1), 70-82, (2019)..

RAWSON, J., Western Zhou Ritual Bronzes from the Arthur M. Sackler Collections. Arthur M. Sackler Foundation, Washington, D.C. (1990). 
SO, J., Eastern Zhou ritual bronzes in the Arthur M. Sackler Collections, Arthur M. Sackler Foundation, Washington, DC. (1995).

WANG, H., A short history of Chinese numismatics in European languages. Early China 35, 395-429 (2013).

WANG, H., COWELL, M., CRIBB, J. and BOWMAN, S. (eds.), Metallurgical Analysis of Chinese Coins at the British Museum. British Museum Research Publications 152, London (2005).

WATSON, B., Records of the Grand Historian of China (Sima Qian). Columbia University Press, New York (1961). (2 vols.).

ZHOU WEIRONG and DAI ZHIQIANG, Qianbixue yu yezhu shi luncong (Papers on Numismatics and the History of Metallurgy). Zhonghua shuju, Beijing (2002).

ZHOU WEIRONG, Zhongguo gudai qianbi hejin chengfen yanjiu (Chinese Coins. Alloy Composition and Metallurgical Research). Zhongghua shiju, Beijing (2004). 


\section{Appendix: The 'Unit Sum' Problem}

It is important to know whether the trends discussed here are real and not an artefact of the bound nature of what is essentially a ternary system in which \%Cu $+\% \mathrm{~Pb}+\% \mathrm{Sn}=100$. This 'Unit Sum' problem has been recognized for many years as a potential issue when dealing with chemical compositional data - the fact that major element compositional data is constrained to add up to $100 \%$ leads inevitably to an interdependence between the constituent elements. Aitchison $(1986$, xiii) has stated that the interpretation of such data is 'fraught with danger'. In summary, the unit sum problem can be explained as follows. The simple definition of the concentration of a component expressed as a percentage involves not only the concentration of that particular element, but also the sum of the concentrations of all other elements, i.e., in a ternary copper, lead and tin alloy, the percentage of copper is calculated as:

$$
\text { wt } \% \mathrm{Cu}=\frac{[\mathrm{Cu}]}{[\mathrm{Cu}]+[\mathrm{Pb}]+[\mathrm{Sn}]} \times 100
$$

where square brackets denote the determined weight of each element. Generalizing,

$$
\mathrm{wt} \% \mathrm{Cu}=\frac{[\mathrm{Cu}]}{\sum[\text { all elements }]} \times 100
$$

or

$$
\mathrm{wt} \% \mathrm{Cu}=f[\text { all elements }]
$$

This inevitably leads to correlations between elemental concentrations arising from this constraint. This has been pointed out systematically since 1982, particularly in relation to the interpretation of geochemical data (Aitchison 1982, 1984, 1999; Aitchison et al. 2000).

In 1986, Aitchison proposed the use of logratos to counter these problems, by generating variables that are independent of each other. It should be noted that this use of logratios has been challenged (Tangri and Wright 1993) (but rebutted in Aitchison et al. 2002), or at least met with a degree of caution (Baxter et al. 2005) in the statistical world, and in many areas of geochemistry the unit sum problem continues to be ignored. It is also true to say that it has been widely adopted as a means of avoiding the problem by a number of 
tephrochronologists (e.g., Stokes and Lowe 1988, Stokes et al. 1992, Pollard et al. 2006), who rely on making chemical comparisons between groups of vitreous tephra sherds.

Aitchison (1986) proposed the use of a number of different logratios to address particular problems:

i) the natural log of all possible component ratios;

ii) the natural log of the ratio of all other components to a common component;

iii) the natural log of the ratio of all component values to the geometric mean of all components in a particular sample (the 'centred logratio').

In order to investigate whether the trend lines observed in this study of Chinese pre-Qin coinages are an artefact of the Unit Sum Problem, we have used approach ii) to decouple the variables. In the case of an (approximately) ternary system (where $\% \mathrm{Cu}+\% \mathrm{~Pb}+\% \mathrm{Sn}=$ $100)$, this gives the relatively simple approach of calculating $\ln (\mathrm{Pb} / \mathrm{Cu})$ and $\ln (\mathrm{Sn} / \mathrm{Cu})$, which can then be plotted as a bivariate scattergram.

Figure 1 shows a plot of $\% \mathrm{~Pb}$ vs \% Sn for all of the pre-Qin coinage, together with the modelled data for an alloy composed of $80 \% \mathrm{Cu}, 15 \% \mathrm{Sn}$ and $5 \% \mathrm{~Pb}$ diluted with increasing proportions of i) a mixture of $50 / 50 \mathrm{Cu} / \mathrm{Pb}$ and ii) pure $\mathrm{Pb}$, as shown in Figure 5 of the text. As noted in the text, this suggests that most of the data can be explained by dilution of a 'stock' bronze with $50 / 50 \mathrm{Cu} / \mathrm{Pb}$, but not by simple additions of lead. 


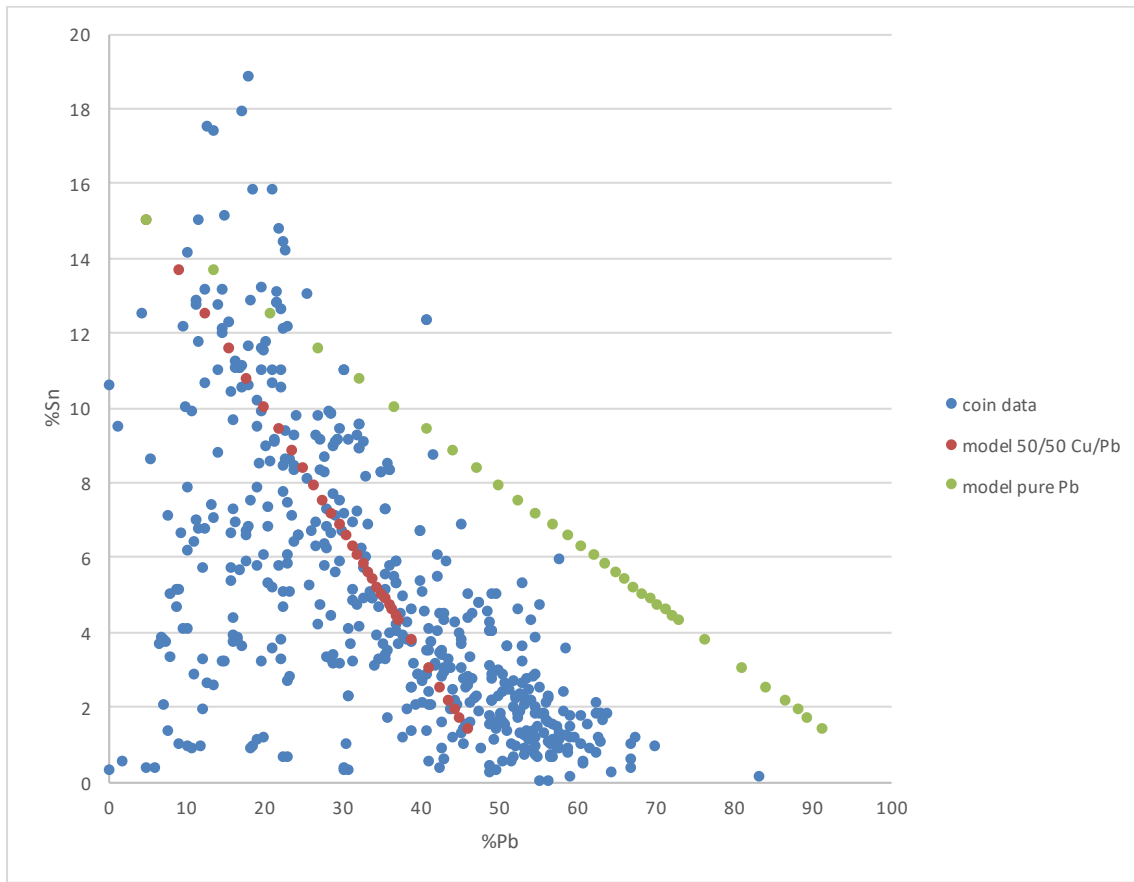

Figure 1. \%Sn vs \%Pb for all pre-Qin coinage, with superimposed trend line for an alloy of $80 \% \mathrm{Cu}, 15 \% \mathrm{Sn}$ and $10 \% \mathrm{~Pb}$ diluted with a) pure $\mathrm{Pb}$, and b) 50/50 Cu/Pb.

Figures 2 and 3 show the same data, but plotted as $(\mathrm{Pb} / \mathrm{Cu})$ vs $(\mathrm{Sn} / \mathrm{Cu})$ and $\ln (\mathrm{Pb} / \mathrm{Cu})$ and $\ln (\mathrm{Sn} / \mathrm{Cu})$.

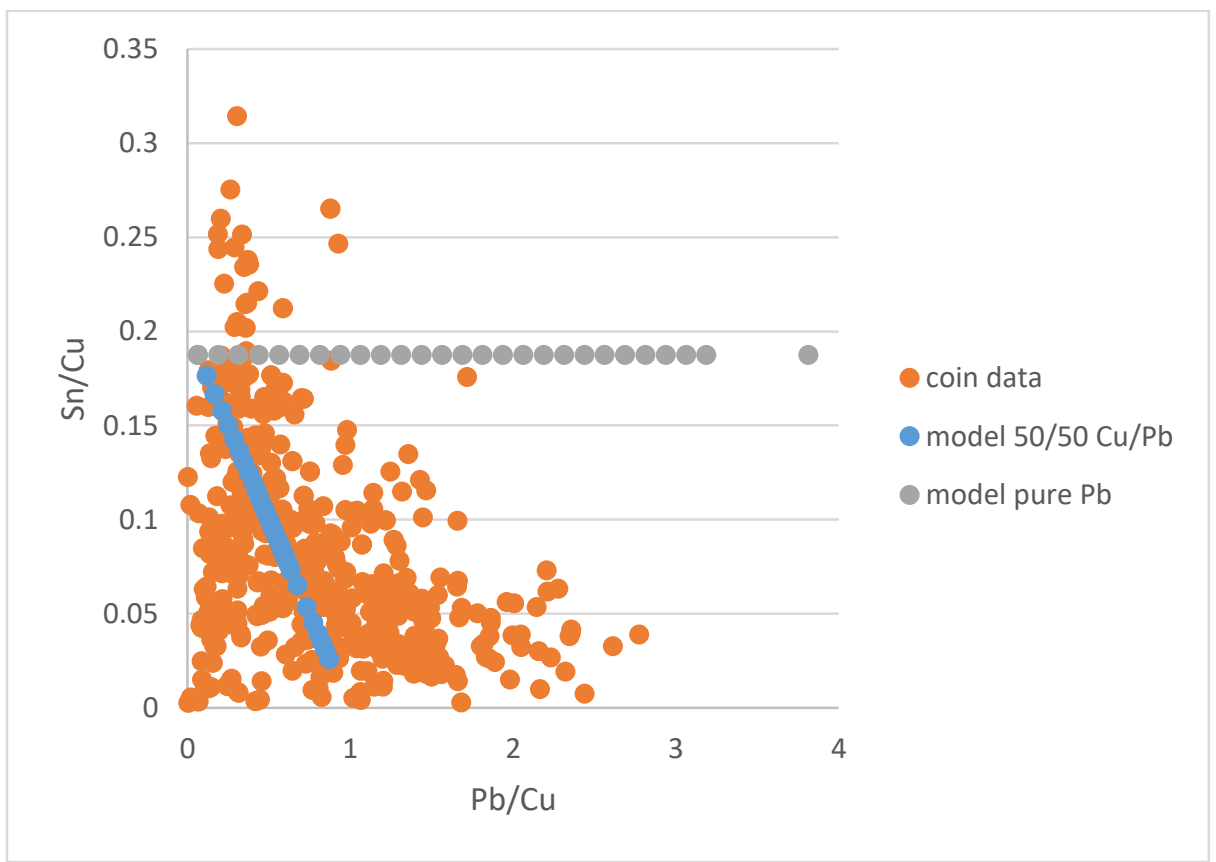

Figure 2. As Figure 1, but plotted as $\mathrm{Pb} / \mathrm{Cu}$ vs $\mathrm{Sn} / \mathrm{Cu}$. 


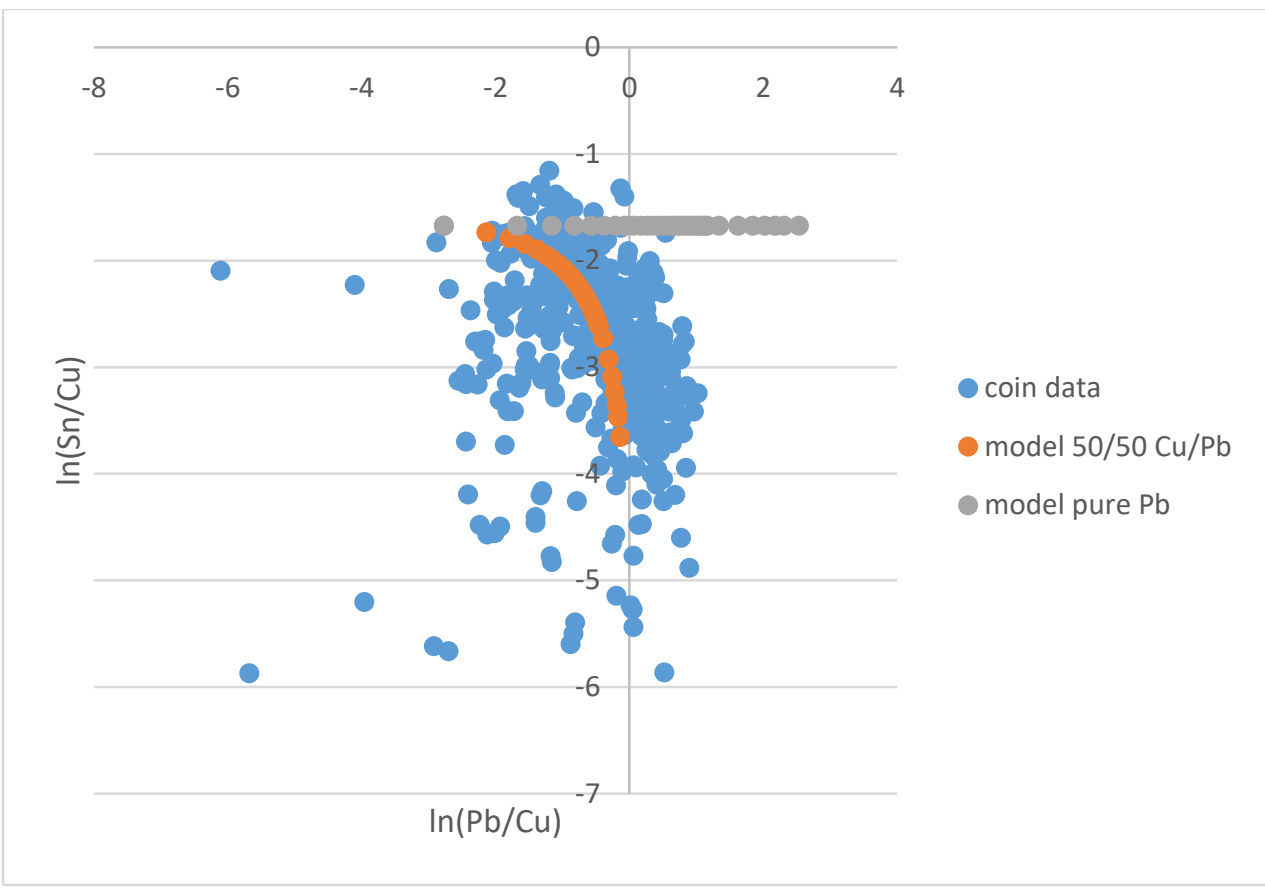

Figure 3. As Figure 1, but plotted as $\ln (\mathrm{Pb} / \mathrm{Cu})$ vs $\ln (\mathrm{Sn} / \mathrm{Cu})$.

Figure 2 shows very clearly that the addition of pure lead to a 'stock' bronze does not fit the data - the value of $\mathrm{Sn} / \mathrm{Cu}$ is invariant with $\mathrm{Pb} / \mathrm{Cu}$, as would be expected from the addition of a diluting material which contains no tin, and does not therefore change the original $\mathrm{Sn} / \mathrm{Cu}$ ratio. This is also shown in Figure 3. The main point to draw here is that the trend lines shown in Figure 1 are still supported in Figures 2 and 3, in which the variables have been decoupled. We may conclude that the proposed trends observed in the data are not an artefact of the Unit Sum problem. 


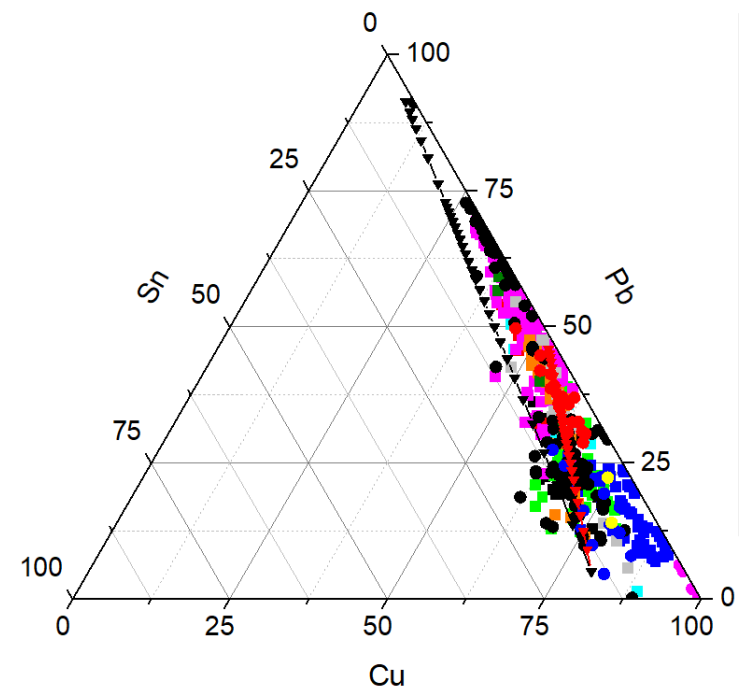

- 1.1 Hollow-handle spades

- 1.2. Pointed-foot spades and similar square-foot spades

- 1.3. Square foot spades

- 1.4. Arched-foot spade

1.5. Other spades

- 2.1 Yan Knives

- 2.2. Qi Knives

2.3 Straight Knives

- 2.4. Other knives

- 3. Ant-nosed money

- 4.1. Yi hua

- 4.2 Banliang and Liangzao

- 4.3 Yuanzi

4.4 Ming yue

Figure 4. The same data as Fig. 1, but plotted as a ternary (Cu-Pb-Sn) diagram.

Finally, Figure 4 shows a ternary ( $\mathrm{Cu}-\mathrm{Pb}-\mathrm{Sn})$ diagram of the same raw data as used to produce Figure 1, together with the same two modelled dilution trends. Again this makes clear that the primary effect for the majority of the data is best explained by a dilution with with $50 / 50 \mathrm{Cu} / \mathrm{Pb}$ rather than with pure lead.

Each method of presentation has advantages. Figure 1 (plotting \% $\mathrm{Pb}$ vs \% $\mathrm{Sn}$ ) is most easily related to the original data, but does not account for concomitant changes in copper, whereas Figures 2 and 3 are both more robust in terms of having independent axes and presenting all the variables (since copper is included), but are less intuitive to interpret. The ternary diagram (Figure 4) again presents all the data, but the diagrams are less easy to draw. Hence, in this paper, we have chosen to present the data as in Figure 1.

\section{References}

AITCHISON, J., The statistical analysis of compositional data. Journal of the Royal Statistical Society Series B - Methodology 44, 139-177 (1982).

AITCHISON, J., The statistical analysis of geochemical compositions. Journal of the International Association for Mathematical Geology 16, 531-564 (1984). 
AITCHISON, J., The Statistical Analysis of Compositional Data. Blackburn Press, Caldwell, NJ (1986). (reprinted 2003).

AITCHISON, J., Logratios and natural laws in compositional data analysis. Mathematical Geology 31, 563-580 (1999).

AITCHISON, J., BARCELÓ-VIDAL, C., MARTÍN-FERNÁNDEZ, J.A. and PAWLOWSKY-GLAHN, V., Logratio analysis and compositional distance. Mathematical Geology 32, 271-275 (2000).

AITCHISON, J., BARCELÓ -VIDAL, C. and PAWLOWSKY-GLAHN, V., Some comments on compositional data analysis in archaeometry, in particular the fallacies in Tangri and Wright's dismissal of logratio analysis. Archaeometry 44, 295-304 (2002).

BAXTER, M.J., BEARDAH, C.C., COOL, H.E.M. and JACKSON, C.M., Compositional data analysis of some alkaline glasses. Mathematical Geology 37, 183-196 (2005).

POLLARD, A.M., BLOCKLEY, S.P.E. and LANE, C.S., Some numerical considerations in the geochemical analysis of distal microtephra. Applied Geochemistry 21 1692-1714 (2006).

STOKES, S. and LOWE, D.J., Discriminant Function Analysis of late Quaternary tephras from five volcanoes in New Zealand using glass shard major element chemistry. Quaternary Research 30, 270-283 (1988).

STOKES, S., LOWE, D.J. and FROGGATT, P.C., Discriminant Function Analysis and correlation of late Quaternary rhyolithic tephra deposits from Taupo and Okataina volcanoes, New Zealand, using glass shard major element composition. Quaternary International 13-14, 103-117 (1992).

TANGRI, D. and WRIGHT, R.V.S., Multivariate analysis of compositional data: applied comparisons favour standard principal components over Aitchison's loglinear contrast method. Archaeometry 35, 103-112 (1993).

\section{Data Generated by Models}

a) 'Stock' bronze ( $80 \% \mathrm{Cu}, 5 \% \mathrm{~Pb}, 15 \% \mathrm{Sn})$ plus $50 / 50 \mathrm{Cu} / \mathrm{Pb}$

$\begin{array}{llllllll}\text { Dilution } & \mathrm{Cu} & \mathrm{Pb} & \mathrm{Sn} & \mathrm{Pb} / \mathrm{Cu} & \mathrm{Sn} / \mathrm{Cu} & \ln (\mathrm{Pb} / \mathrm{Cu}) & \operatorname{In}(\mathrm{Sn} / \mathrm{Cu}) \\ 0 & 80 & 5 & 15 & 0.0625 & 0.1875 & -2.7726 & -1.674 \\ 10 \% & 77.2727 & 9.0909 & 13.6364 & 0.1176 & 0.1765 & -2.1401 & -1.7346 \\ 20 \% & 75 & 12.5 & 12.5 & 0.1667 & 0.1667 & -1.7918 & -1.7918 \\ 30 \% & 73.0769 & 15.3846 & 11.5385 & 0.2105 & 0.1579 & -1.5581 & -1.8458 \\ 40 \% & 71.4286 & 17.8571 & 10.7143 & 0.25 & 0.15 & -1.3863 & -1.8971 \\ 50 \% & 70 & 20 & 10 & 0.2857 & 0.1429 & -1.2528 & -1.9459 \\ 60 \% & 68.75 & 21.875 & 9.375 & 0.3182 & 0.1364 & -1.1451 & -1.9924 \\ 70 \% & 67.6471 & 23.5294 & 8.8235 & 0.3478 & 0.1304 & -1.0561 & -2.0369\end{array}$




\begin{tabular}{|c|c|c|c|c|c|c|c|c|}
\hline $80 \%$ & 66.6667 & 25 & 8.3333 & 0.375 & 0.125 & -0.9808 & -2.0794 & \\
\hline $90 \%$ & 65.7895 & 26.3158 & 7.8947 & 0.4 & 0.12 & -0.9163 & -2.1203 & \\
\hline $100 \%$ & 65 & 27.5 & 7.5 & 0.4231 & 0.1154 & -0.8602 & -2.1595 & $\begin{array}{l}\text { 1:1 bronze }+ \\
\text { diluent }\end{array}$ \\
\hline $110 \%$ & 64.2857 & 28.5714 & 7.1429 & 0.4444 & 0.1111 & -0.8109 & -2.1972 & \\
\hline $120 \%$ & 63.6364 & 29.5455 & 6.8182 & 0.4643 & 0.1071 & -0.7673 & -2.2336 & \\
\hline $130 \%$ & 63.0435 & 30.4348 & 6.5217 & 0.4828 & 0.1034 & -0.7282 & -2.2687 & \\
\hline $140 \%$ & 62.5 & 31.25 & 6.25 & 0.5 & 0.1 & -0.6931 & -2.3026 & \\
\hline $150 \%$ & 62 & 32 & 6 & 0.5161 & 0.0968 & -0.6614 & -2.3354 & \\
\hline $160 \%$ & 61.5385 & 32.6923 & 5.7692 & 0.5313 & 0.0938 & -0.6325 & -2.3671 & \\
\hline $170 \%$ & 61.1111 & 33.3333 & 5.5556 & 0.5455 & 0.0909 & -0.6061 & -2.3979 & \\
\hline $180 \%$ & 60.7143 & 33.9286 & 5.3571 & 0.5588 & 0.0882 & -0.5819 & -2.4277 & \\
\hline $190 \%$ & 60.3448 & 34.4828 & 5.1724 & 0.5714 & 0.0857 & -0.5596 & -2.4567 & \\
\hline $200 \%$ & 60 & 35 & 5 & 0.5833 & 0.0833 & -0.539 & -2.4849 & $\begin{array}{l}\text { 1:2 bronze }+ \\
\text { diluent }\end{array}$ \\
\hline $210 \%$ & 59.6774 & 35.4839 & 4.8387 & 0.5946 & 0.0811 & -0.5199 & -2.5123 & \\
\hline $220 \%$ & 59.375 & 35.9375 & 4.6875 & 0.6053 & 0.0789 & -0.5021 & -2.539 & \\
\hline $230 \%$ & 59.0909 & 36.3636 & 4.5455 & 0.6154 & 0.0769 & -0.4855 & -2.5649 & \\
\hline $240 \%$ & 58.8235 & 36.7647 & 4.4118 & 0.625 & 0.075 & -0.47 & -2.5903 & \\
\hline $250 \%$ & 58.5714 & 37.1429 & 4.2857 & 0.6341 & 0.0732 & -0.4555 & -2.615 & \\
\hline $300 \%$ & 57.5 & 38.75 & 3.75 & 0.6739 & 0.0652 & -0.3947 & -2.73 & $\begin{array}{l}\text { 1:3 bronze + } \\
\text { diluent }\end{array}$ \\
\hline $400 \%$ & 56 & 41 & 3 & 0.7321 & 0.0536 & -0.3118 & -2.9267 & \\
\hline $500 \%$ & 55 & 42.5 & 2.5 & 0.7727 & 0.0455 & -0.2578 & -3.091 & \\
\hline $600 \%$ & 54.2857 & 43.5714 & 2.1429 & 0.8026 & 0.0395 & -0.2199 & -3.2321 & \\
\hline $700 \%$ & 53.75 & 44.375 & 1.875 & 0.8256 & 0.0349 & -0.1917 & -3.3557 & \\
\hline $800 \%$ & 53.3333 & 45 & 1.6667 & 0.8438 & 0.0313 & -0.1699 & -3.4657 & \\
\hline $1000 \%$ & 52.7273 & 45.9091 & 1.3636 & 0.8707 & 0.0259 & -0.1385 & -3.655 & $\begin{array}{l}\text { 1:10 bronze } \\
\text { +diluent }\end{array}$ \\
\hline
\end{tabular}

a) 'Stock' bronze ( $80 \% \mathrm{Cu}, 5 \% \mathrm{~Pb}, \mathbf{1 5 \%} \mathrm{Sn})$ plus pure $\mathrm{Pb}$

\begin{tabular}{|c|c|c|c|c|c|c|c|c|}
\hline Dilution & $\mathrm{Cu}$ & $\mathrm{Pb}$ & Sn & $\mathrm{Pb} / \mathrm{Cu}$ & $\mathrm{Sn} / \mathrm{Cu}$ & $\ln (\mathrm{Pb} / \mathrm{Cu})$ & $\ln (\mathrm{Sn} / \mathrm{Cu})$ & \\
\hline 0 & 80 & 5 & 15 & 0.0625 & 0.1875 & -2.7726 & -1.674 & \\
\hline $10 \%$ & 72.7273 & 13.6364 & 13.6364 & 0.1875 & 0.1875 & -1.674 & -1.674 & \\
\hline $20 \%$ & 66.6667 & 20.8333 & 12.5 & 0.3125 & 0.1875 & -1.1632 & -1.674 & \\
\hline $30 \%$ & 61.5385 & 26.9231 & 11.5385 & 0.4375 & 0.1875 & -0.8267 & -1.674 & \\
\hline $40 \%$ & 57.1429 & 32.1429 & 10.7143 & 0.5625 & 0.1875 & -0.5754 & -1.674 & \\
\hline $50 \%$ & 53.3333 & 36.6667 & 10 & 0.6875 & 0.1875 & -0.3747 & -1.674 & \\
\hline $60 \%$ & 50 & 40.625 & 9.375 & 0.8125 & 0.1875 & -0.2076 & -1.674 & \\
\hline $70 \%$ & 47.0588 & 44.1176 & 8.8235 & 0.9375 & 0.1875 & -0.0645 & -1.674 & \\
\hline $80 \%$ & 44.4444 & 47.2222 & 8.3333 & 1.0625 & 0.1875 & 0.0606 & -1.674 & \\
\hline $90 \%$ & 42.1053 & 50 & 7.8947 & 1.1875 & 0.1875 & 0.1719 & -1.674 & \\
\hline $100 \%$ & 40 & 52.5 & 7.5 & 1.3125 & 0.1875 & 0.2719 & -1.674 & $\begin{array}{l}\text { 1:1 bronze }+ \\
\text { diluent }\end{array}$ \\
\hline $110 \%$ & 38.0952 & 54.7619 & 7.1429 & 1.4375 & 0.1875 & 0.3629 & -1.674 & \\
\hline
\end{tabular}




\begin{tabular}{|c|c|c|c|c|c|c|c|c|}
\hline $120 \%$ & 36.3636 & 56.8182 & 6.8182 & 1.5625 & 0.1875 & 0.4463 & -1.674 & \\
\hline $130 \%$ & 34.7826 & 58.6957 & 6.5217 & 1.6875 & 0.1875 & 0.5232 & -1.674 & \\
\hline $140 \%$ & 33.3333 & 60.4167 & 6.25 & 1.8125 & 0.1875 & 0.5947 & -1.674 & \\
\hline $150 \%$ & 32 & 62 & 6 & 1.9375 & 0.1875 & 0.6614 & -1.674 & \\
\hline $160 \%$ & 30.7692 & 63.4615 & 5.7692 & 2.0625 & 0.1875 & 0.7239 & -1.674 & \\
\hline $170 \%$ & 29.6296 & 64.8148 & 5.5556 & 2.1875 & 0.1875 & 0.7828 & -1.674 & \\
\hline $180 \%$ & 28.5714 & 66.0714 & 5.3571 & 2.3125 & 0.1875 & 0.8383 & -1.674 & \\
\hline $190 \%$ & 27.5862 & 67.2414 & 5.1724 & 2.4375 & 0.1875 & 0.891 & -1.674 & \\
\hline $200 \%$ & 26.6667 & 68.3333 & 5 & 2.5625 & 0.1875 & 0.941 & -1.674 & $\begin{array}{l}\text { 1:2 bronze }+ \\
\text { diluent }\end{array}$ \\
\hline $210 \%$ & 25.8065 & 69.3548 & 4.8387 & 2.6875 & 0.1875 & 0.9886 & -1.674 & \\
\hline $220 \%$ & 25 & 70.3125 & 4.6875 & 2.8125 & 0.1875 & 1.0341 & -1.674 & \\
\hline $230 \%$ & 24.2424 & 71.2121 & 4.5455 & 2.9375 & 0.1875 & 1.0776 & -1.674 & \\
\hline $240 \%$ & 23.5294 & 72.0588 & 4.4118 & 3.0625 & 0.1875 & 1.1192 & -1.674 & \\
\hline $250 \%$ & 22.8571 & 72.8571 & 4.2857 & 3.1875 & 0.1875 & 1.1592 & -1.674 & \\
\hline $300 \%$ & 20 & 76.25 & 3.75 & 3.8125 & 0.1875 & 1.3383 & -1.674 & $\begin{array}{l}1: 3 \text { bronze }+ \\
\text { diluent }\end{array}$ \\
\hline $400 \%$ & 16 & 81 & 3 & 5.0625 & 0.1875 & 1.6219 & -1.674 & \\
\hline $500 \%$ & 13.3333 & 84.1667 & 2.5 & 6.3125 & 0.1875 & 1.8425 & -1.674 & \\
\hline $600 \%$ & 11.4286 & 86.4286 & 2.1429 & 7.5625 & 0.1875 & 2.0232 & -1.674 & \\
\hline $700 \%$ & 10 & 88.125 & 1.875 & 8.8125 & 0.1875 & 2.1762 & -1.674 & \\
\hline $800 \%$ & 8.8889 & 89.4444 & 1.6667 & 10.0625 & 0.1875 & 2.3088 & -1.674 & \\
\hline $1000 \%$ & 7.2727 & 91.3636 & 1.3636 & 12.5625 & 0.1875 & 2.5307 & -1.674 & $\begin{array}{l}\text { 1:10 bronze } \\
\text { +diluent }\end{array}$ \\
\hline
\end{tabular}

